\title{
Effect of Henna Leaves on the Corrosion Inhibition of Tin in Acidic and Alkaline Media
}

\author{
Muhammad Bashir Ibrahim*, Zakariyau Sulaiman, Bishir Usman, Muhammad Adamu Ibrahim \\ Department of Pure and Industrial Chemistry, Bayero University, Kano, Nigeria \\ Email address: \\ mbibrahim.chm@buk.edu.ng (M. B. Ibrahim), zakariyau058@gmail.com (Z. Sulaiman), usmanb@buk.edu.ng (B. Usman), \\ mibrahim042@gmail.com(M. A. Ibrahim) \\ ${ }^{*}$ Corresponding author
}

\section{To cite this article:}

Muhammad Bashir Ibrahim, Zakariyau Sulaiman, Bishir Usman, Muhammad Adamu Ibrahim. Effect of Henna Leaves on the Corrosion Inhibition of Tin in Acidic and Alkaline Media. World Journal of Applied Chemistry. Vol. 4, No. 4, 2019, pp. 45-51.

doi: 10.11648/j.wjac.20190404.11

Received: August 27, 2019; Accepted: September 19, 2019; Published: October 9, 2019

\begin{abstract}
The corrosion inhibition behaviour of Henna leaves on Tin in $1.0 \mathrm{M} \mathrm{HCl}$ and $1.0 \mathrm{M} \mathrm{NaOH}$ was investigated using weight loss technique at temperatures ranges, $25-50^{\circ} \mathrm{C}$. The maximum inhibition efficiency was found to be 95.45 at optimum inhibitor concentration. The presence of the compound adsorbed on the tin coupons was verified by spectroscopic measurements of the surface before and after corrosion tests. The leaves extract of Lawsonia inermis was found to be more effective in alkaline solution. It also confirmed that the inhibition efficiency decreased with increased in temperature but increased with increasing inhibitor concentrations. The Activation energy, Gibbs free energy were found to be $28.131,29.589$ $\mathrm{kJmol}^{-1} ;-3.280,-3.245 \mathrm{kJmol}^{-1}$ in acidic and alkaline media respectively. The adsorption was found to obey Freundlich isotherm with linear coefficient $\left(\mathrm{R}^{2}\right)$ and equilibrium parameter $\mathrm{K}_{\mathrm{ads}}$ to be $0.972,0.957 ; 0.06,0.05$ for both systems in acidic and alkaline media respectively. Physical adsorption mechanism is proposed from the trend of $\Delta \mathrm{G}_{\mathrm{ads}}$. The negative values of $\Delta \mathrm{G}_{\text {ads }}$ shows the spontaneity of the inhibition process. The increase in the activation energy of the inhibition processes with values of $80 \mathrm{~kJ} / \mathrm{mol}$ support the mechanism of physical adsorption process. Lawsonia inermis leaves extract has proved to be more excellent inhibitor for tin in $\mathrm{NaOH}$ alkaline.
\end{abstract}

Keywords: Corrosion, Henna, Tin, Acidic, Alkaline Solution

\section{Introduction}

Corrosion has influenced many industries, causing a lot of damage materials leading to huge economic losses. Plants had been recognized as sources of naturally occurring compounds, some with rather complex molecular structures and having varying degrees of physical, chemical and biological properties [1-3]. There has been a wide spread research on the use of plant extracts as corrosion inhibitors [4-7]. An aqueous extract of plant material Lawsonia inermis $L$ powder had been used in hydrochloric acid as a corrosion inhibitor in controlling corrosion of carbon steel immersed in an aqueous solution containing $60 \mathrm{ppm}$ of $\mathrm{Cl}^{-}$, by the mass loss method in the absence and presence of $\mathrm{Zn}^{2+}$ [8]. The main constituent of this plant extract is Lawsone. It has excellent inhibition efficiency (IE) and shows excellent IE at pH 6, 8 and 12. In the presence of $\mathrm{Zn}^{2+}$ there exists a synergistic effect. The protective film has been analysed using Fourier transform infrared (FTIR) spectroscopy [8]. The film consists of $\mathrm{Fe}^{2+}$ - Lawsone complex and Zinc hydroxide. It is found to be UV-fluorescent. Electrochemical studies such as potentio dynamic polarization and alternating current (AC) impedance have been used to find the mechanistic aspects of corrosion inhibition. Corrosion inhibition of carbon steel in the presence of different concentrations of aqueous extract from henna leaves in $1 \mathrm{M} \mathrm{HCl}$ solution using the weight loss and potention dynamic polarization methods [9]. The effect of temperature on the corrosion behaviour of carbon steel was investigated in the temperature range 293-333 K. The inhibition efficiency increases with increasing inhibitor concentration but decreases with increasing temperature. The activation and free energies for the inhibition reactions support the mechanism of physical adsorption. The potentio dynamic polarization measurements indicate that henna extract acts as a mixed type inhibitor. 
Surface and protective film analysis have been carried out using; energy dispersive X-ray (EDX), scanning electron microscopy (SEM), Fourier transforms infrared (FT-IR) spectroscopy and $\mathrm{X}$-ray diffraction (XRD) analysis. The dyeing properties and corrosion inhibition of Lawsonia inermis $L$ were attributed to the presence of Lawsone, 2-hydroxy-1, 4-naphthaquinone having colour index number 75486 [10]. As contribution to the current interest on environmentally friendly, green corrosion inhibitors, there is need to look at the leaves of Henna as an effective potential corrosion inhibitor in both acidic and alkaline solution. Therefore, the present study investigates the possibility of using Henna leaves powder for the inhibition of the corrosion of tin in $\mathrm{HCl}$ and $\mathrm{NaOH}$ solutions using the mass loss method The mechanisms of the reactions are proposed below.



Figure 1. Henna in acidic medium forms of lawsone.

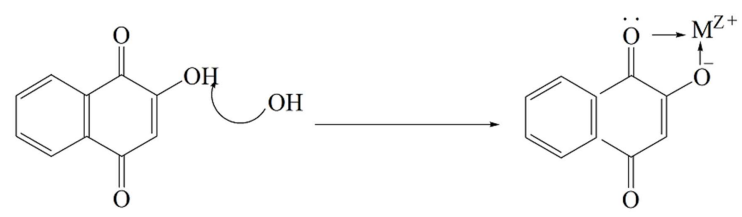

Figure 2. Henna in bcidic medium forms of lawsone.

In the acidic solution of Henna (Figure 1), the oxygen atom in the lawsone might protonated easily, because there is high electron density on it leading to positively charged inhibitor species while in the basic solution (Figure 2), the hydrogen atom of the phenolic group in lawsone can be deprotonated by the high electron density of hydroxides ions from the base leading to negatively charged inhibitor species. The adsorption can occur via electrostatic interaction between the negatively charged molecules and the positively charged metal surface leading to physisorption of the inhibitor molecules. Further co-ordinate bond may occur between unshared $\mathrm{e}^{-}$pairs of unprotonated oxygen atom of the inhibitor and vacant d-orbital of metal surface atoms [9].

\section{Materials and Method}

All the reagents used in this research were of analytical grade and deionised water was used for their preparation. The Tin sheet used for the study is obtained from Metal Focus Fabrication Technology Incubation Centre complex, Farm centre Kano state, Nigeria. The sheet was mechanically pressedcut into coupons, each of dimensions $2.0 \mathrm{~cm} \times 2.0 \mathrm{~cm} \times 0.001$ $\mathrm{cm}$, containing a small hole drilled near the upper edge. Each coupon was clean with Emery paper of different grade (10 by 100 ) by washing with distilled water degreased by ethanol, dipped in acetone and allowed to dry in air and preserved in a desiccator prior to experimental [11]. Fresh leaves of the henna plant were obtained from Tudun Yola garden in Gwale Local
Government Area, Kano and identified at the Plant Science Department of Bayero University, Kano, Nigeria. The leaves were then washed with deionised water after collection and air dried. The leaves were pulvarised in to fine powder form and were sieved to pass through a $250 \mathrm{~nm}$ meshed sieve. The corrodent solutions were prepared for $1.0 \mathrm{M} \mathrm{HCl}$ and $\mathrm{NaOH}$ concentration. The concentration of the stock acid was calculated using the formula $\mathrm{M}=10 \%$ purity $\mathrm{d} / \mathrm{Mr}$ where, $\mathrm{M}$ is the molarity, $\mathrm{d}$ is the density and $\mathrm{Mr}$ is the relative molecular mass. From which certain volume of the stock acid was measured into $1000 \mathrm{~cm}^{3}$ volumetric flask contained deionised water and made up to the mark with the deionised water to give the new concentration required by serial dilution method. Also $40.0 \mathrm{~g}$ of sodium hydroxide pellet was weighed in a $500 \mathrm{~cm}^{3}$ beaker and then dissolved the solid with deionised water. The mixture was transferred quantitatively to the $1000 \mathrm{~cm}^{3}$ volumetric flask and made up to the mark with deionised water. This is $1.0 \mathrm{M} \mathrm{NaOH}$ solution. The henna solution was prepared by weighing $1.0 \mathrm{~g}$ of the henna powder in to $1000 \mathrm{ml}$ volumetric flask containing 1.0 M Hydrochloric acid solution, made up to the mark with test solution, shake to dissolved and left to stand for 24 hours. This represent the stock solution of the inhibitor $(1000 \mathrm{mg} / \mathrm{L})$ from which various concentrations of $10,20,30,40$ and $50 \mathrm{mg} / \mathrm{L}$ were prepared by serial dilution respectively. Similar procedure was repeated with $1 \mathrm{M}$ sodium hydroxide solution [12]. A previously treated and weighed coupon was separately and completely immersed in a $100 \mathrm{ml}$ beaker containing the test solution at a specified concentration with and without the inhibitor. The beaker was inserted into a thermostated water bath: Medical instrument MFG. CO. 400013 maintained at a specified temperature. The coupon was withdrawn from the test solution at intervals of time, it was then washed with deionised water and light brush, dried in acetone and reweighed. The difference in weight was taken as the weight loss due to corrosion to test the effect of temperature and inhibitor concentration [11]. FTIR analysis (Cary 630 FTIR Spectrometer Agilent Technologies) using Attenuated total reflection technique was used to identify the major functional groups and bond present.

\section{Result and Discussion}

The degree of surface coverage $(\Theta)$, inhibition efficiency (\%I. E) of the inhibitor and corrosion rates (CR in $\mathrm{mm} / \mathrm{y}$ ) were calculated from the average weight loss using Equations 1,2 and 3.

$$
\begin{gathered}
\theta=\frac{\Delta \mathrm{w}_{1}-\Delta \mathrm{w}_{2}}{\Delta \mathrm{w}_{1}} \\
\% 1 . \mathrm{E}=\frac{\Delta \mathrm{w}_{1}-\Delta \mathrm{w}_{2}}{\Delta \mathrm{w}_{1}} \times 100
\end{gathered}
$$

Where $\Delta \mathrm{w}_{1}$ and $\Delta \mathrm{w}_{2}$ are the weight loss of the metal in uninhibited and inhibited solution, respectively. 


$$
\text { Corrosion rate }(\mathrm{mm} / \mathrm{y})=\frac{\Delta \mathrm{w} \times 87.6}{\mathrm{~A} \times \mathrm{t} \times \mathrm{d}}
$$

Where, $\Delta \mathrm{w}$ is weight loss in $\mathrm{mg}, \mathrm{A}$ is area of specimen in $\mathrm{cm}^{2}, \mathrm{t}$ is time of exposure in hours, $\mathrm{d}$ is the density of metal in $\mathrm{g} / \mathrm{cm}^{3}$ and 87.6 is a constant number known as reactivity constant of tin. The basic process of metallic corrosion in aqueous solution consists of the anodic dissolution of metal and the cathodic reduction of oxidants present in the solution. A typical example of this is when tin is placed in hydrochloric acid it dissolves forming Tin chloride with the release of hydrogen gas. Similarly, $\mathrm{NaOH}$ solution attack tin which dissolves forming sodium stannate (a colourless complex salt and octahedral in shape) with the release of hydrogen gas. During metallic corrosion, the rate of oxidation equals to the rate of reduction in terms of electron production and consumption [13].

\subsection{Effect of Temperature on the Corrosion Rate of Tin}

Table 1 shows the variation of corrosion rate in the absence of the inhibitor at temperature range 298-323 K. From Table 1 it can be observed that there is a slightly increase in weight loss as the temperature is increased from 298 - $323 \mathrm{~K}$. This observation implies that temperature favours the reactivity of the active constituents of the corrosion media. A rise in the temperature usually increases the rate of hydrogen evolution reaction on the cathode, which results in a higher metal corrosion rate. This shows that the dissolution of the metal coupons increased at higher temperatures. It is also evident that a combination of higher temperatures produced higher weight loss with time, thus higher rate of reaction. This observation is attributed to the rate of chemical reaction, which says that chemical reaction increases with increasing temperatures [14].

Table 1. Temperature effect in the corrosion rate of $\mathrm{HCland} \mathrm{NaOH}$ on Tin.

\begin{tabular}{|c|c|c|c|c|c|}
\hline $\mathbf{S} / \mathbf{N}$ & Temperature (K) & Average weight loss in Acid (g) & Average weight loss in Alkaline (g) & Acid C. R (mm/y) & Alkaline C. R (mm/y) \\
\hline 1 & 298 & 0.0026 & 0.0021 & 37960 & 22995 \\
\hline 2 & 303 & 0.0027 & 0.0022 & 39420 & 24090 \\
\hline 3 & 308 & 0.0028 & 0.0024 & 40880 & 26280 \\
\hline 4 & 313 & 0.0030 & 0.0026 & 43800 & 28470 \\
\hline 5 & 318 & 0.0032 & 0.0027 & 46720 & 29565 \\
\hline 6 & 323 & 0.0035 & 0.0029 & 51100 & 31755 \\
\hline
\end{tabular}

\subsection{Effect of Inhibitors on the Corrosion of Tin Metal}

However, inhibition decreases with increase in temperature. From Tables 2 and 3, it can be observed also that as temperature change from 323 to 303 in the presence of an inhibitor at optimum concentration, there is a corresponding decrease in the weight loss and decrease in the corrosion rate in the range $17520-110 \mathrm{~mm} / \mathrm{y}$ resulted in the higher inhibition efficiency 93.1 and $95.45 \%$. The maximum inhibition efficiency is lower at $323 \mathrm{~K}$ than at $303 \mathrm{~K}$. This is in agreement with what is known about the dependence of adsorption on temperature, that as temperature rises, the quantity adsorbed decreases and as a result of this, the isotherm of higher temperatures are lower than that of lower temperatures [15].

There was a general reduction in the weight loss of tin sheet in the solutions containing lawsoniainermis compared to the uninhibited solutions. Tables 2 and 3 shows the variation of corrosion rate in the presence of inhibitor with varying concentration of inhibitors at $323 \mathrm{~K}$ and $303 \mathrm{~K}$ respectively, it also shows the values of inhibition efficiencies and degree of surface coverage obtained from weight loss measurement of different concentrations of Henna extract as compared to the weight loss and corrosion rates of tin in free acid and alkaline solutions at 303 and 323 $\mathrm{K}$ in a thermostatic water bath. From the data it was observed that corrosion rate was significantly lowered down in presence of the inhibitors than in their absent and also it is clear that the surface coverage $(\theta)$ increases with increasing concentration of inhibitor but decreases with increase in temperature. This effect is hugely marked at optimum concentration $(0.5 \%)$ of the inhibitors. The corrosion rate was found dependent on the concentration of inhibitors and temperature. The decreasing corrosion rate and increasing inhibition efficiency was attributed to the adsorption of inhibitor on the metal surface blocked the corrosion sites of metal surface [16]. This shows that the Henna extract bonded and adheres on the surface of corroding environment and produced a protective film on the metal. The adsorbed films of the inhibitors act as physical barrier between metal surface and corrosion media [8]. The structure of the active compound is as shown in scheme 1 and 2 under the discussion of the inhibition mechanism of the reaction mixture.

Table 2. The Inhibition efficiency (IE) of Henna extract in 1.0 M HCl and $1.0 \mathrm{M} \mathrm{NaOH}$ Solutions for 3 hrs and 4 hrs respectively at $323 \mathrm{~K}$.

\begin{tabular}{|c|c|c|c|c|c|c|c|c|}
\hline \multirow{2}{*}{ INH. Conc. (mg/L) } & \multicolumn{4}{|c|}{ ACIDIC MEDIUM } & \multicolumn{4}{|c|}{ BASIC MEDIUM } \\
\hline & Wt. loss (g) & $\operatorname{DSC}(\theta)$ & IE (\%IE) & $\mathrm{CR}(\mathrm{mm} / \mathrm{y})$ & Wt. loss (g) & $\operatorname{DSC}(\theta)$ & IE (\% IE) & $\mathrm{CR}(\mathrm{mm} / \mathrm{y})$ \\
\hline 10 & 0.0026 & 0.2571 & 25.71 & 37960 & 0.0020 & 0.3103 & 31.03 & 21900 \\
\hline 20 & 0.0018 & 0.4857 & 48.57 & 26280 & 0.0017 & 0.4138 & 41.38 & 18615 \\
\hline 30 & 0.0015 & 0.5714 & 57.14 & 21900 & 0.0013 & 0.5517 & 55.17 & 14235 \\
\hline 40 & 0.0012 & 0.6571 & 65.71 & 17520 & 0.0008 & 0.7241 & 72.41 & 8760 \\
\hline 50 & 0.0008 & 0.7714 & 77.14 & 11680 & 0.0002 & 0.9310 & 93.10 & 2190 \\
\hline
\end{tabular}


Table 3. The Inhibition efficiency (IE) of Henna extract in $1.0 \mathrm{M} \mathrm{HCl}$ and $1.0 \mathrm{M} \mathrm{NaOH}$ Solutions for 3hrs and 4hrs respectively at 303K.

\begin{tabular}{lllllllll}
\hline \multirow{2}{*}{ INH. Conc. (mg/L) } & \multicolumn{2}{l}{ ACIDIC MEDIUM } & \multicolumn{5}{l}{ BASIC MEDIUM } \\
\cline { 2 - 8 } & Wt. loss (g) & DSC $(\boldsymbol{\theta})$ & IE $(\%$ IE) & CR (mm/y) & Wt. loss (g) & DSC $(\boldsymbol{\theta})$ & IE $(\%$ IE) & CR (mm/y) \\
\hline 10 & 0.0013 & 0.5185 & 51.90 & 18980 & 0.0011 & 0.5000 & 50.00 & 12045 \\
20 & 0.0011 & 0.5926 & 59.26 & 16060 & 0.0009 & 0.5909 & 59.09 & 9855 \\
30 & 0.0009 & 0.6667 & 66.67 & 13140 & 0.0005 & 0.7727 & 77.27 & 5475 \\
40 & 0.007 & 0.7407 & 74.07 & 10220 & 0.0003 & 0.8640 & 86.40 & 329 \\
50 & 0.0004 & 0.8519 & 85.19 & 5840 & 0.0001 & 0.9545 & 95.45 & 110 \\
\hline
\end{tabular}

\subsection{Adsorption and Thermodynamic Study}

Equations (4), is Freundlich isotherm equations and its dimensionless equilibrium parameters Where, $\mathrm{K}_{\mathrm{ads}}$ is the adsorption equilibrium constant, 55.5 is the water concentration, $\mathrm{C}$ is the inhibitor concentration and $\mathrm{a}$ is the adsorbate interaction parameter, (5) is a thermodynamics equations for activation energy of corrosion process where, A is Arrhenius preexponential frequency factor, $\mathrm{T}$ is the absolute temperature, $\mathrm{R}$ is the universal gas constant, Ea is a quantity characteristic of the adsorption known as activation energy. Equation (6) is a Gibb's free energy of adsorptions, (7) and (8) were used to find the enthalpy, entropy and free energy of uninhibited corrosion processes [17]. The plot of $\log \Theta$ against inhibitor concentration $(\mathrm{mg} / \mathrm{L})$ displays a straight line for the tested inhibitor in the acidic and alkaline media using equation (4). The linear plots, with high correlation coefficient $\left(\mathrm{R}^{2}\right)$ as presented in Figure 3 with slope of about unity in both media, clearly reveal that the surface adsorption process of the inhibitor molecules on the tin surface followed the Freundlich adsorption isotherm which gives relative higher values of $\mathrm{K}_{\mathrm{ads}}=0.06$ and 0.05 for both system in acidic and alkaline media respectively. This indicates that the adsorbing species occupies typical adsorption site at the good fit inhibitors. Generally larger $\mathrm{K}$ values imply more efficient adsorption, hence a better inhibitive performance [12, 17]. The adsorption of the inhibitor on to the surface of Tin is retarded by increase in temperature supporting the mechanism of physical adsorption. A negative surface charge will favour the adsorption of cations whereas anion adsorption is favoured by a positive surface charge [18]. The ability of $\mathrm{Cl}^{-}$and $\mathrm{OH}^{-}$ions in hydrochloric acid and sodium hydroxide to be strongly adsorbed on the metal surface and hence facilitate physical adsorption. Arrhenius equation was used to study the effect of temperature [18]. The calculated values for the activation energy, the free energy of both uninhibited and inhibited process of the system can be observed in Table 4. From the result obtained the activation energy of basic medium was found to be higher than acidic medium which indicates reaction in basic solution require the higher energy as such take a longer time for the corrosion process. The central idea here is that for the $1.0 \mathrm{M}$ solution of the acid and base to attack the tin, its molecules must then be activated over an energy barrier equal to the $\mathrm{Ea}$ of the $\mathrm{HCl}$ and $\mathrm{NaOH}$ solutions and its temperature dependent. If the values of $\mathrm{Ea}>80 \mathrm{~kJ} / \mathrm{mol}$, it indicates chemical adsorption and when $\mathrm{Ea}<80$ $\mathrm{kJ} / \mathrm{mol}$ means physical adsorption [19]. All the estimated values of the activated energy in this work were found to be less than $80 \mathrm{~kJ} / \mathrm{mol}$ which implies physical adsorption [16]. The negative values of $\Delta \mathrm{G}_{\text {ads }}^{0}$ ensure the spontaneity of adsorption process as well as stability of the adsorbed layer on the tin surface. Generally, the values of $\Delta \mathrm{G}_{\text {ads }}^{0}$ around $-20 \mathrm{~kJ} / \mathrm{mol}$ or lower are consistent with physical adsorption [15].

$$
\begin{gathered}
\log \theta=\log \mathrm{K}+\mathrm{n} \log \mathrm{C} \\
\log (\mathrm{CR})=\log \mathrm{A}-\mathrm{Ea} /(2.303 \mathrm{RT}) \\
\Delta \mathrm{G}_{\mathrm{ads}}=-2.303 \mathrm{RT} \log \left[55.5 \mathrm{~K}_{\mathrm{ads}}\right] \\
\log \left(\frac{\mathrm{CR}}{\mathrm{T}}\right)=\log \left(\frac{\mathrm{R}}{\mathrm{Nh}}\right)+\frac{\Delta \mathrm{S}_{\text {corr }}}{2.303 \mathrm{R}}-\frac{\Delta \mathrm{H}_{\text {corr }}}{2.303 \mathrm{RT}} \\
\Delta \mathrm{G}_{\text {corr }}=\Delta \mathrm{H}_{\text {corr }}-\mathrm{T} \Delta \mathrm{S}_{\text {corr }}
\end{gathered}
$$

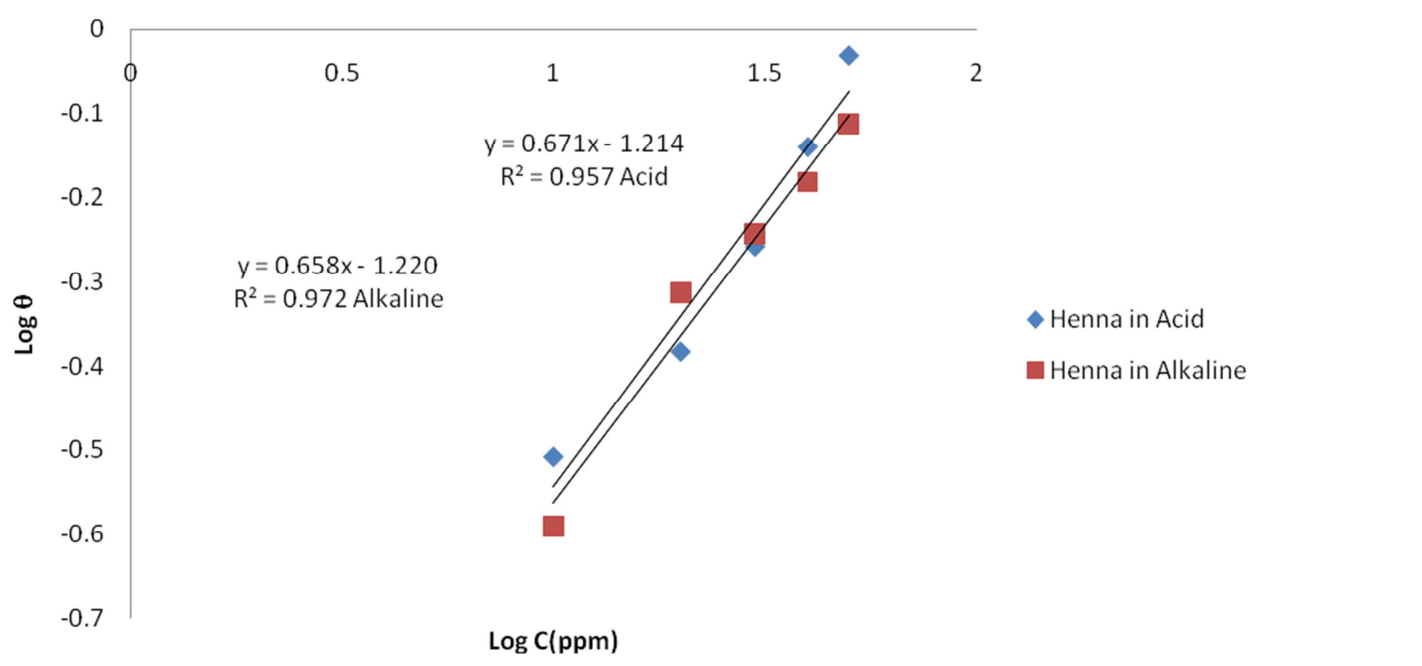

Figure 3. Freundlich Isotherms for Henna in the Acidic and Alkaline Media. 
Table 4. Calculated Kinetic, Thermodynamic Parameters for the corrosion Process without Inhibitor.

\begin{tabular}{|c|c|c|c|c|c|c|c|}
\hline Acid & & & & Alkaline & & & \\
\hline Ea & $\Delta \mathbf{G}_{\text {corr. }}$ & $\Delta \mathbf{H}$ & $\Delta \mathbf{S}$ & Ea & $\Delta \mathbf{G}_{\text {corr. }}$ & $\Delta \mathbf{H}$ & $\Delta \mathrm{S}$ \\
\hline $9.405 \mathrm{~kJ} / \mathrm{mol}$ & $-75.539 \mathrm{~kJ} / \mathrm{mol}$ & $6.826 \mathrm{~kJ} / \mathrm{mol} / \mathrm{K}$ & $0.255 \mathrm{~kJ} / \mathrm{mol}$ & $10.562 \mathrm{~kJ} / \mathrm{mol}$ & $-74.382 \mathrm{~kJ} / \mathrm{mol}$ & $7.983 \mathrm{~kJ} / \mathrm{mol} / \mathrm{K}$ & $0.255 \mathrm{~kJ} / \mathrm{mol}$ \\
\hline
\end{tabular}

Table 5. Calculated Kinetic, Thermodynamic Parameters and equilibrium constant of Adsorbed Inhibitor system.

\begin{tabular}{llllll}
\hline Acid & \multicolumn{5}{c}{ Alkaline } \\
\hline Ea & $\boldsymbol{\Delta} \mathbf{G}_{\text {ads. }}$ & $\mathbf{K}_{\text {ads }}$ & $\mathbf{E a}$ & $\Delta \mathbf{G}_{\text {ads. }}$ & $\mathbf{K}_{\text {ads }}$ \\
\hline $28.131 \mathrm{~kJ} / \mathrm{mol}$ & $-3.245 \mathrm{~kJ} / \mathrm{mol}$ & 0.0603 & $29.589 \mathrm{~kJ} / \mathrm{mol}$ & $-3280 \mathrm{~kJ} / \mathrm{mol}$ & 0.0611 \\
\hline
\end{tabular}

\subsection{Analysis of the Protective Film}

The tin interaction with Henna is due to the presence of free oxygens located at position 2 and 6 and likely the presence of $\pi$-electrons as presented in the scheme 1 and 2 . The $\mathrm{C}=\mathrm{O}$ bond ranges from 1630 to $1820 \mathrm{~cm}^{-1}$. The results were confirmed by FTIR spectra of Plant extract and Snsheet surface immersed in $1 \mathrm{M} \mathrm{HCl}$ and $1 \mathrm{M} \mathrm{NaOH}$ with 50 $\mathrm{mg} / \mathrm{L}$ of Henna extract (Figure 4a-d). The main constituent of Henna extract is lawsone, it contains benzene unit, pbenzoquinone unit and phenolic group. The-OH bond ranges from 3200-3650 $\mathrm{cm}^{-1}$ [19]. The phenolic $-\mathrm{OH}$ stretching appears at $3272 \mathrm{~cm}^{-1}$. The peaks at 2920 and $2106 \mathrm{~cm}^{-1}$ can be assigned to aliphatic and aromatic $\mathrm{C}-\mathrm{H}$. The aromatic $\mathrm{C}=\mathrm{C}$ stretching frequency appeared at $1441 \mathrm{~cm}^{-1}$. The $\mathrm{C}=\mathrm{O}$ stretching frequency appeared at $1728 \mathrm{~cm}^{-1}$. The FTIR spectra of the protective film formed on the metal surface after immersion in $\mathrm{HCl}$ and $\mathrm{NaOH}$ solutions are shown in Figure $4 \mathrm{a}-\mathrm{d}$ respectively. It is found that almost all the peaks observed for Henna extract are also identified for Sn-sheet immersed in $1 \mathrm{M} \mathrm{HCl}$ and $1 \mathrm{M} \mathrm{NaOH}$ solution containing 50 $\mathrm{mg} / \mathrm{L}$ of Henna extract. The phenolic $-\mathrm{OH}$ stretching has shifted from $3272 \mathrm{~cm}^{-1}$ to 3305 and $3650 \mathrm{~cm}^{-1}$ in the acidic medium and $3281 \mathrm{~cm}^{-1}, 3558 \mathrm{~cm}^{-1}$ in the basic medium. The aromatic $\mathrm{C}=\mathrm{C}$ stretching shifted from $1441 \mathrm{~cm}^{-1}$ to $1460 \mathrm{~cm}^{-1}$ and $1458 \mathrm{~cm}^{-1}$ in the $\mathrm{HCl}$ and $\mathrm{NaOH}$ solution respectively. The $\mathrm{C}=\mathrm{O}$ stretching frequency has been shifted from 1728 $\mathrm{cm}^{-1}$ to $1743 \mathrm{~cm}^{-1}$ in both $\mathrm{HCl}$ and $\mathrm{NaOH}$ solutions. This indicates formation of Tin-Plant extract complexes or salts. The phenol group of lawsone will donate electron to the metal in order to achieve its noble state of orbit, while the metal would receive the electron to become more stable, hence the metal surface could be protected from the corrosion attack by hindering the redox process [21].
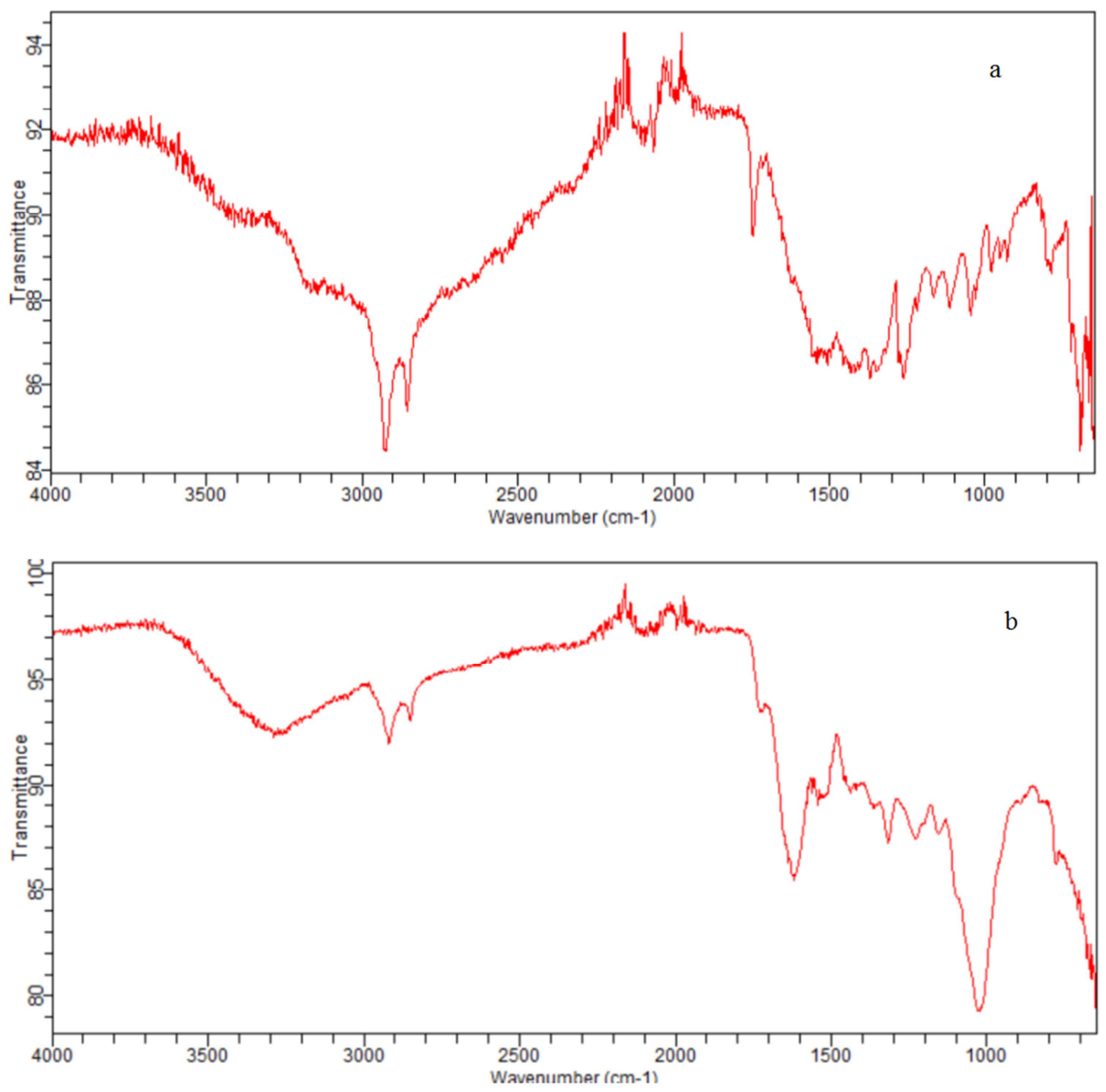

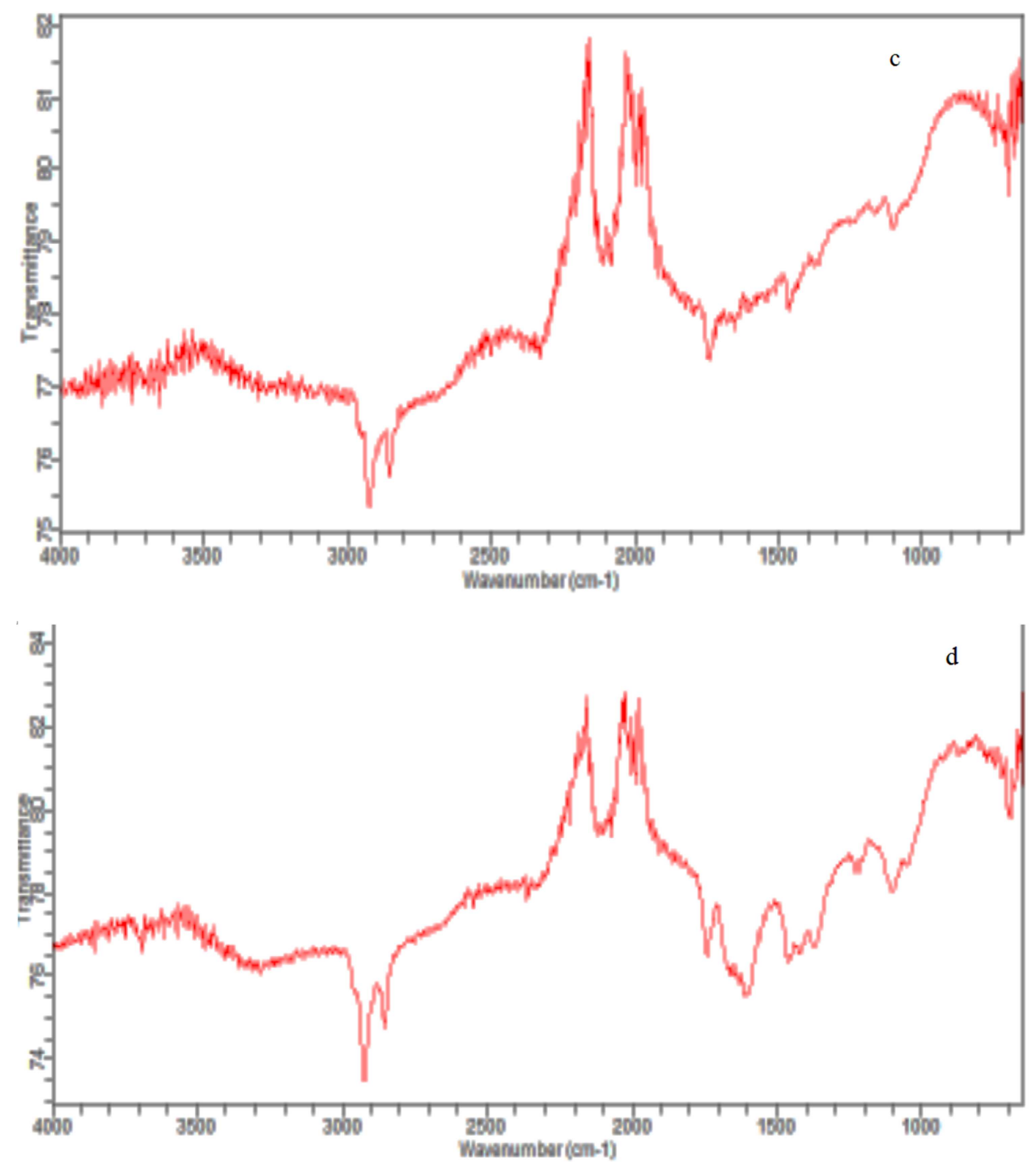

Figure 4. FTIR absorbance spectra analysis of (a) pure tin before corroding (b) Henna leaves powder (c) tin in $1.0 \mathrm{M} \mathrm{HCl}$ with Henna and (d) tin in $1.0 \mathrm{M}$ $\mathrm{NaOH}$ with Henna.

\section{Conclusion}

The corrosion inhibition behaviour of Lawsonia inermis leaves extract on tin metal in $1 \mathrm{M}$ acid and base were investigated using weight loss method. The calculate results showed that, the corrosion rate increases with increase in temperature over time, the optimum temperature were determined at $50^{\circ} \mathrm{C}$ in $1 \mathrm{M}$ acid and alkaline solutions respectively. The inhibition was found to be maximum at an optimum concentration and low temperature due to the inhibitive action of Lawsonia inermis leaves extract. Lawsonia inermis leaves extract has proved to be more excellent inhibitor for tin in $\mathrm{NaOH}$ alkaline solution due to the presence of Lawsone. The adsorption takes place via physical adsorption mechanism and Freundlich adsorption model best described the inhibition process. The presence of the compound adsorbed on the tin coupons was verified by spectroscopic measurements of the surface before and after corrosion tests.

\section{References}

[1] Oguzie EE. Corrosion inhibition of aluminum in acidic and alkaline media by Sansevieria trifasciata extract. Corros. Sci. 2007; Vol 49: pp 1527-1539.

[2] Raja PB, Sethuraman MG. Natural products as corrosion inhibitor for metals in corrosive media. Mater. Lett. 2008; Vol 62: pp 113-116.

[3] Raja PB, Sethuraman MG. Inhibitive effect of black pepper extract on the sulphuric acid corrosion of mild steel. Mater. Lett. 2008; Vol 62: pp 2977-2979.

[4] Raja PB, Sethuraman MG. Strychnos nux-vomica an ecofriendly corrosion inhibitor for mild steel in $1 \mathrm{M}$ sulphuric acid medium. Mater. Corros. 2009; Vol 22: pp 22-28.

[5] Sangeetha M, Rajendran S, Muthumegala TS, Krishanaveni A. Green corrosion inhibitors-An Overview. Zastitamaterijala. 2011; Vol 5: pp 3-19. 
[6] Farooqi HI, Quraishi MA, Saini PA. Natural compounds as corrosion inhibitors for mild steel in industrial cooling systems. European Federation of corrosion. 1997; Vol 1: pp 186-194.

[7] Mukherjee D, Berchman J, Rajsekkar A, Sundarsanan N, Mahalingam R, Maruthamuthu S, Thiruchelvam T, Karaikudi, D. Plant-based alkaloids inhibit corrosion of marine alloys. Anti-Corros Method Material. 1997; Vol 44: pp 186-194.

[8] Rajendran. S, Agasta. M., Devi. B. R, Devi. S. B, Rajam. k. and JEYASUNDARI (2009). Corrosion Inhibition by an Aqueous Extract of Henna Leaves (LawsoniaInermis L). Scientific paper UDC: 620.1934, Vol 20: pp 77-83.

[9] Hamdy. A. and Nour Sh. El-Gendy (2012). Thermodynamic, adsorption and electrochemical Studies for Corrosion inhibition of carbon Steel by Henna Extract in acid Medium. Egyptian Journal of Petroleum, Vol 1: pp 17-24.

[10] Al-Sehaibani. H (2000). Evaluation of Extraction of Henna leaves as Environmentally Friendly Corrosion Inhibitor for Metals. Materialwisson Schaftund work Stofftochnlk, Vol 31 (12): pp 1060-1063.

[11] Muhammad A. A. Uzairu A, Iyun J. F, Abba H. (2014). The use of Glutamic Acid as Corrosion Inhibitor for Aluminium in $\mathrm{HCl}$ Solution. IOSR Journal of Applied Chermistry, Vol 7: pp 45-49.

[12] Nnanna L. A., Anozie I. U, Avoaja A. G. I., Akoma C. S. And Eti E. P (2011). Comparative Study of Corrosion Inhibition of Auminium Alloy of Type AA3003 in Acidic and Alkaline Media by Euphorbia Hirta Extract. African Journal of Pure and Applied Chemistry Vol. 5 (8): pp 265-271.

[13] Sharma. K. S (2012). Basics of Corrosion Chemistry. Published by Wiley-VCH Verlag GmbH and Co. KGaA, Vol 1: pp 1-6.
[14] James A. O. and Akaranta O., (2009). The Inhibition of Corrosion of Zinc in 2.0 M Hydrochloric acid Solution with Acetone Extract of red Onion Skin. African Journal of Pure and Applied Chemistry, Vol 3 (11): pp 212.

[15] Nwabanne, J. T. and Okafor, V. N., (2011). Inhibition of the Corrosion of Mild Steel in Acidic Medium by Vernonia Amygdalina: Adsorption and thermodynamics Study. Journal of Emerging Trends in Engineering and Applied Sciences, Vol 2 (4): pp 619-625.

[16] Ituen, E. B., Udo, U. E., Odozi, N. W. and Dan, E. U. (2013). Adsorption and Kinetic/Thermodynamic Characterization of Aluminium Corrosion Inhibition in Sulphuric Acid by Extract of Astoniaboonei. IOSR Journal of Applied Chemistry, Vol 3: pp 52-59.

[17] Rani, A. B. E. and Basu, J. B. B (2012). Green Inhibitors for Corrosion Protection of Metals and Alloys: An Overview. International Journal of Corrosion, Vol 1: pp 1-15.

[18] Kaewprasit C., Hequet, E., Abidi, N., and Gouriot, J. P., (1998). Application of methylene blue adsorption to cotton fiber specific surface area measurement: Part 1. Methodology. Journal of. Corrosion Science Vol 2 (164): pp 173.

[19] Cruz J., Martínez-Palou R., Genesca J., García-Ochoa E, (2004). Experimental and Theoretical Study of 1-(2ethylamino)-2-methylimidazoline as an Inhibitor of Carbon Steel Corrosion in Acid Media. Journal of Electroanalytical Chemistry. Vol 566 (1): pp 111-121.

[20] Robert G. A. and Francis A. C (1990). Organic Chemistry: A Brief Course Second Edition. WCB/ McGraw-Hill, USA New York Mexico City, pp 491-517.

[21] Hasan K. S. and Sisodia. P (2011). Paniala (Flacourtia Jangomes) Plant Extract as Ecofriendly Inhibitor on the Corrosion of Mild Steel in Acidic Media. Rasayan Journal of Chemistry, Vol 4 (3): pp 548-553. 